\title{
ALGUNOS DATOS SOBRE EL ORIGEN DE LA TÉCNICA DE LA PINTURA MURAL HISPANOMUSULMANA
}

\author{
Ana García Bueno y Víctor J. Medina Flórez \\ Universidad de Granada
}

\section{Introducción}

Este trabajo está incluido en una de las líneas de investigación del Departamento de Pintura de la Facultad de Bellas Artes de Granada, dedicada al estudio de la pintura hispanomusulmana. En ella uno de los interrogantes que nos planteamos es el origen de la técnica de ejecución, cuestión que ya preocupaba a Torres Balbás en su artículo «Los zócalos pintados en la arquitectura hispanomusulmana». En este artículo, referencia obligada en el estudio de la pintura mural de este periodo histórico, ya se planteaba si la técnica respondía a una tradición local o había sido traída por los musulmanes de Oriente ${ }^{1}$.

En este trabajo nos centraremos fundamentalmente en la exposición de los resultados obtenidos en el examen de los materiales de diversos ejemplos de pinturas relacionadas con estos posibles orígenes de la técnica para su posterior comparación con los obtenidos en pinturas peninsulares de época califal.

Comenzamos haciendo referencia al estudio de pinturas murales romanas procedentes de Guadix ${ }^{2}$. Por otra parte, como cabe la posibilidad de que en las sucesivas oleadas de población civil vinieran artistas que introdujeran variantes en la técnica o incluso una renovación completa de la misma, tomamos como obra de referencia para el estudio de la pintura musulmana de Oriente las pinturas de Qusayr 'Amra en Jordania (siglo VIII), correspondientes a un primer momento de la expansión, por considerarlas uno de los ejemplos más interesantes no sólo de la pintura del período Omeya, sino de todo el arte Islámico (declaradas patrimonio de la humanidad por la UNESCO).

1 Torres Balbás, L., «Los zócalos pintados en la arquitectura hispanomusulmana». Al-Andalus, VII (1942), 395-419.

${ }^{2}$ García Bueno, A.; Adroher Auroux, A.; López Pèrtiñez, M.C. y Medina Flórez, V.J.; «Estudio de materiales y técnica de ejecución de los restos de pintura mural romana hallados en una excavación de Guadix, Granada», Espacio, Tiempo y Forma, Serie I, Prehistoria y Arqueología, 3, (2000), 247-273.

Al-Qanțara XXIII, 1 (2002) 213-222 
Los casos seleccionados para el estudio de la primera pintura hispanomusulmana, para poder establecer semejanzas y diferencias con las anteriores, son los fragmentos procedentes de Medina Elvira de Granada (hoy en el Museo Arqueológico de Granada) y otros de Córdoba, concretamente un fragmento de Madinat al-Zahrā' depositado en el Museo Arqueológico de esta ciudad y algunos de los zócalos aparecidos en la excavación arqueológica de Arrabales de Poniente.

\section{La pintura mural hispanorromana}

Los resultados obtenidos en el estudio de las pinturas de Guadix ${ }^{3}$ repiten prácticamente los de otros trabajos de pinturas hispanorromanas estudiadas por otros autores 4 .

En lo referente a los pigmentos utilizados, hay que destacar que, tanto los pigmentos naturales, como los artificiales, coinciden plenamente con la paleta que los escritos de Vitrubio y Plinio describen como la más idónea para la pintura mural ${ }^{5}$ :

- Amarillo, a base de oxi-hidróxidos de hierro.

- Rojos, normalmente a base de óxidos de hierro, principalmente hematites. Además se ha constatado la presencia de plomo, que se identifica como minio en este caso. El minio de los romanos es un sulfuro de mercurio que no coincide con la composición del óxido de plomo identificado. Sin embargo, Abad Casal ${ }^{6}$ atribuye esta composición al pigmento que Plinio llama minium secundarium y que se utilizaba para falsificar el primero.

- Negro, color artificial a base de negro de humo.

- Azul, azul egipcio, un vidrio de color azul por la presencia de cobre.

- Verde, tierra verde, formada por meteorización de silicatos de hierro, calcio y magnesio.

- Blanco, carbonato cálcico.

3 Ibidem.

${ }^{4}$ Guiral, C. y Martín-Bueno, M., Bilbilis I: Decoración pictórica y estucos ornamentales, Zaragoza, 1996, 503; García Ramos, G.; Justo Erbez, A. y Abad Casal, L., «Estudio físicoquímico y mineralógico de una serie de pinturas y revestimientos murales de Itálica (Sevilla)», Archivo Español de Arqueología, 49 (1976), 141-157; García Ramos, G.; Linares López, M.D.; Abad Casal, L., «Estudio fisicoquímico y mineralógico de algunas muestras de pinturas y revestimientos murales de Bolonia (Cádiz)», Archivo Español de Arqueología, 50-51 (1977-78), 295-310. Mostalac Carrillo, A.; Beltrán Lloris, Colonia Vitrix Ivlia Lepida-Celsa (Velilla de Ebro, Zaragoza. Estratigrafia, pinturas y cornisa de la casa de los Delfines, Diputación Provincial de Aragón, Zaragoza 1994, 41-125, 333-345.

5 Abad Casal, L.; «Algunas consideraciones sobre los colores romanos y su empleo en pintura», Homenaje a Sáenz de Buruaga, Instituto Pedro de Valencia, Diputación Provincial de Badajoz, 1982 395-406.

6 Ibidem, 403. 
El material que fija los pigmentos es claramente la cal, ya que no se ha detectado la presencia de materia orgánica atribuible a ningún aglutinante; ahora bien, esta cal tiene distintas posibilidades de utilización. Pudo hacerse aplicando los pigmentos sobre el mortero fresco o en seco, mezclando los pigmentos con agua de cal.

El empleo de estos materiales, por tanto, no parece consecuencia de la proximidad o abundancia de los mismos en la zona, sino, más bien, de una misma tradición en la decoración mural que debió extenderse por las provincias del imperio. De modo que la riqueza de los materiales empleados dependía, sobre todo, de la importancia de la edificación.

Del estudio de los materiales constitutivos de los morteros de Guadix se puede constatar que, por ejemplo, se van haciendo más ricos en calcita a medida que son más superficiales; las proporciones del último mortero oscilan en cada caso, pero siempre es más rico en calcita que el mortero que le sirve de base. Por otra parte, se puede comprobar que el árido varía según los casos, siendo una arena compuesta fundamentalmente por silicatos. El más pobre de los morteros superficiales está en torno al 16 por 100 de calcita, mientras que en los otros dos casos las proporciones coinciden, más o menos, con las tradicionalmente utilizadas (una de cal por dos de arena). Las diferencias entre unos morteros y otros pueden deberse a ejecuciones de distinto momento, mano o funcionalidad de la estancia.

Finalmente, la textura lisa de la mayoría de los fragmentos descubiertos, así como el hecho de que no se identifique aglutinante en ellos, hace pensar en la posibilidad de que estas pinturas se pulieran una vez aplicado el color. Las expolitiones permitían obtener una superficie más fina y brillante y además hacían aflorar a la superficie los restos de agua y cal que quedaban en el interior del muro húmedo. Esto permitía que la carbonatación de la capa pictórica fuera mejor y que las extensiones pintadas al fresco fueran mayores.

\section{Pintura mural de Oriente}

Es difícil definir el arte de los Omeyas y su civilización, ya que tanto uno como otra son el resultado del encuentro entre la nueva fe musulmana y las antiguas tradiciones de Oriente Próximo. De modo que, desde los primeros años de la conquista hasta mediados del siglo VIII, las raíces de cada provincia tienen un importante peso en el arte y la cultura de este período ${ }^{7}$.

Centrándonos en la pintura mural de esta zona geográfica, en todo Oriente Medio existía una importante tradición de decoración mural ${ }^{8}$. Nos que-

${ }^{7}$ Ettinghausen, R.; Grabar, O., Arte y Arquitectura del Islam. 650-1250, Manuales de Arte Cátedra, Madrid 1997, 32 y 33.

8 Mora, P.; Mora, L.; Philippot, P., Conservation of Wall Paintings, Londres, 1984, 69-75. 
dan muestras muy importantes de ello en Egipto, donde las condiciones de conservación han permitido su permanencia hasta nuestros días; ejemplos como el de la tumba de Nefertari, en el valle de los Reyes (en el que la acción aglutinante de la capa pictórica la hace la goma arábiga), nos pueden servir de referencia ${ }^{9}$. Por tanto, la técnica utilizada era claramente al seco, los morteros de preparación estaban compuestos por una capa de arena y arcillas con pequeñas cantidades de yeso y carbonato cálcico, a la que, a menudo, se añadía paja cortada.

Los métodos empleados en la pintura mural del mundo bizantino nos llegan a través de tratados como el de Dionisio de Fourna o el de Néctar. Aunque estos tratados son posteriores a las pinturas de Qușayr 'Amra, autores como los Mora consideran que el método utilizado en periodos anteriores no debía variar sustancialmente del descrito en estos tratados. La técnica expuesta es claramente el fresco, haciéndose referencia al pulido de la superficie, que se realizaba después de aplicar las grandes manchas de color y de este modo poder continuar la ejecución de los elementos decorativos al fresco ${ }^{10}$. La pintura bizantina presenta, por tanto, algunos cambios con respecto a la tradición romana, como por ejemplo el hecho de que, en términos generales, los enlucidos de Europa occidental no presenten paja ni pelo animal en su composición, mientras que en Oriente Medio encontramos con frecuencia estos componentes ${ }^{11}$.

\subsection{Las pinturas murales de Qusayr ${ }^{c}$ Amra (Jordania)}

La residencia califal de Quṣayr 'Amra se halla a unos $100 \mathrm{~km}$ al E. de Amman, en plena zona desértica. Posiblemente fue construida en el reinado del califa Walīd I, que gobernó entre el 705 y el $715^{12}$.

Iconográficamente, se puede decir que Qușayr 'Amra, al pertenecer a un período inicial del arte musulmán, tiene una clara influencia del arte bizantino. Los rasgos del arte helenístico son innegables, de él toma la representación del califa, exacta a la que el arte bizantino hace del emperador en su divina maiestas ${ }^{13}$. Esto hace pensar, creemos que con bastante probabilidad, que la influencia de la pintura bizantina también esté presente en este monumento a otros niveles.

9 Palet, A. y Porta, E., «Análisis químico de los pigmentos y aglutinantes empleados en las pinturas murales de la tumba de Nefertari», Actas del VIII Congreso de Conservación de Bienes Culturales de Valencia, 1990, 452-460.

${ }_{10}$ Mora, P.; Mora, L.; Philippot, P., Conservation of Wall Paintings, 108-110.

11 Ibidem, 105-117.

12 Almagro, M.; Caballero, L.; Zozaya, J. y Almagro, A., Qusayr 'Amra residencia y baños Omeyas en el desierto de Jordania, Madrid, 1975, 57.

${ }^{13}$ Blázquez, J. M., "Las pinturas helenísticas de Qusayr 'Amra, (Jordania) y sus fuentes», Archivo Español de Arqueología, 54 (1981), 157-202. 


\subsection{Materiales y técnica de ejecución de Qusayr ${ }^{c}$ Amra}

La técnica coincide básicamente con la empleada en la pintura bizantina, aplicando la capa pictórica sobre una base de morteros de cal y polvo de mármol con adición de paja y arena. Aunque los pigmentos se aglutinan inicialmente con goma arábiga, se identificó carbonato cálcico en las capas de pintura, lo que podría atribuirse a la realización de expolitiones, dada la textura que presenta la superficie. Éstas se realizarían después de aplicar las manchas de color, mejorando así la fijación de los pigmentos por la carbonatación que se produce a nivel superficial. Posteriormente, también con goma arábiga, se aplicarían los detalles más minuciosos, que también podrían someterse a nuevos procesos de pulido.

Por tanto, este aglutinante se utilizaría para facilitar la aplicación del pigmento y su uso sería consecuencia del conocimiento que de este material se tenía en este área geográfica y del buen comportamiento que, a nivel de conservación, ha tenido en la misma por las características climatológicas de la zona, extremadamente seca.

En cuanto a los pigmentos, cabe resaltar la riqueza cromática que debieron tener estas pinturas, dada la gran variedad de pigmentos identificados y la pureza de los mismos: albayalde, negro, lapislázuli, cinabrio o bermellón, minio, oropimente o rejalgar, tierra roja y tierra verde.

Todos estos pigmentos están debidamente documentados en los textos clásicos y también en numerosos estudios sobre los materiales de la pintura mural romana. Si tenemos en cuenta los pigmentos habitualmente utilizados en la pintura de este período histórico, podemos observar que en 'Amra, salvo el azul, todos están dentro de esta tradición. De modo que únicamente este pigmento podría estar más relacionado con la pintura oriental, en la que la proximidad geográfica de las minas de lapislázuli y el comercio existente con la zona de extracción hacía más factible su utilización.

\section{Pintura mural califal}

Hay que pensar que en un primer momento, aunque las edificaciones estuvieran muy relacionadas con la propia arquitectura peninsular, las aportaciones orientales debieron existir y por tanto influir tanto en la técnica de ejecución de las primeras pinturas hispano-mu- sulmanas como en los motivos decorativos utilizados ${ }^{14}$.

En general, se puede decir que la pintura mural califal se caracteriza por su simplicidad en los motivos decorativos, con tramas muy elementales. La

14 Morales Martínez, A., 1995, «A la sombra de Damasco. Arquitectura en al-Andalus hasta la proclamación del califato de Córdoba», La arquitectura del Islam Occidental, Barcelona, 43. 
policromía es muy reducida, limitándose al almagra y el blanco y en algunos casos el ocre, aunque éste es mucho menos abundante; ninguno de los casos seleccionados para este estudio presentaba restos de este pigmento, aunque su empleo está comprobado ${ }^{15}$.

\subsection{La pintura mural califal: Medina Elvira, Granada, Madinat al-Zahrä'y Arrabales de Poniente, Córdoba}

En el estudio de la pintura califal nos centraremos en tres ejemplos sumamente significativos. En ellos encontramos dos tipologías técnicas claramente diferenciadas: el primer tipo, los restos de Medina Elvira (Museo Arqueológico de Granada), presenta unas características técnicas específicas que los hacen muy interesantes. Su aspecto es similar al esgrafiado, en el cual el color blanco se obtiene por la eliminación de la capa roja superpuesta, aplicada de forma continua. El segundo corresponde a las pinturas procedentes de Córdoba, concretamente un fragmento de Madīnat al-Zahrā' (Museo Arqueológico de Córdoba) y algunos de los zócalos aparecidos en la excavación de arrabales de Poniente. En todos ellos la decoración es de color almagra y el blanco se obtiene al dejar sin pintar el último de los morteros.

Entre las primeras construcciones documentadas del arte islámico están la mezquita de Elvira y la de Zaragoza, ambas se hacen aprovechando construcciones precedentes ${ }^{16}$. La destrucción de Medina Elvira se produjo en el año 400 de la Hégira, concretamente en los primeros años del siglo XI ${ }^{17}$.

La creación de Madīnat al-Zahrā' obedece al continuo aumento del aparato burocrático de la corte. Además se sabe que, tras la autoproclamación de 'Abd al-Rahmmān III en el año 929, se produce un crecimiento de la ciudad de Córdoba, que se había iniciado anteriormente, pero que en ese momento, en el que probablemente se edificaron los arrabales de Poniente, fue "objeto de una cuidada planificación y una homogeneización en cuanto a los materiales y técnicas constructivas" 18 .

Según las últimas excavaciones llevadas a cabo en Córdoba, la casa de período califal concentraba su escasa decoración en las estancias que se situaban en los lados norte y sur del patio. Estas estancias estaban decoradas con zócalos de color almagra, en ocasiones con motivos decorativos muy sencillos ${ }^{19}$.

15 Gómez Moreno, M., Medina Elvira, Granada, 1986, 9.

16 Morales Martínez, A., «A la sombra de Damasco», 43.

17 Gómez Moreno, M., Medina Elvira, 13.

18 Íbidem, 69-70.

19 Murillo, J.F.; Fuertes, C.; Luna, D., «Aproximación al análisis de los espacios domésticos en la Córdoba andalusí», F. R. García Verdugo y F. Acosta Ramírez (coor.), 


\subsection{Materiales y técnica de ejecución de las pinturas de Medina Elvira}

El sistema de trabajo de estas pinturas puede relacionarse con la pintura mural romana, como por ejemplo el de las pinturas de Narbona, donde el empleo de incisiones repite el proceso descrito para Medina Elvira ${ }^{20}$, y también con el de una casa musulmana de Valencia, que presentan las mismas características ${ }^{21}$. Además la relación con los esgrafiados medievales segovianos, de claro origen islámico ${ }^{22}$, parece evidente.

La aplicación de los materiales inorgánicos en Medina Elvira está muy clara: sobre un mortero de cal cuyo árido mayoritario es la calcita, probablemente polvo de mármol por su pureza y blancura, se aplicó una capa continua de color almagra, sobre la que se hace el dibujo inciso que servirá de base para la ejecución de la composición; ésta se obtiene por la eliminación o esgrafiado de algunas porciones de la trama trazada en el dibujo preparatorio. Se ha podido comprobar que para la eliminación de esta capa de color no se utilizaban plantillas.

La alternancia de color es la verdadera protagonista de la decoración. En todos los casos examinados el color rojo está compuesto por una tierra roja (silicatos con un alto contenido en oxi-hidróxidos de hierro) y el blanco por carbonato cálcico procedente tanto del árido empleado como de la carbonatación del aglomerante.

En cuanto al uso de los aglutinantes detectados existen varias posibilidades; la más factible nos parece la siguiente: sobre un mortero de cal mezclado con cola animal se aplicaría una capa roja de almagra aglutinada con goma arábiga, esta goma impregnaría el mortero seco o semi-seco a través de los poros. Posteriormente, mediante el espatulado de la superficie, se haría migrar los restos de humedad e hidróxido cálcico que quedaran en el interior de la capa de mortero, lo que reforzaría en gran medida la fijación del color y además aportaría este brillo característico de las pinturas pulidas que se puede observar en la mayoría de los fragmentos de pintura procedentes de esta excavación.

El empleo de cola en el mortero de cal no es muy coherente con la técnica del fresco; sin embargo, es conocido el empleo de aditivos orgánicos en los morteros para dotar a los mismos de determinadas características, como

Córdoba en la historia. La construcción de la urbe. Actas del Congreso, Córdoba, 20-23 de mayo, 1997, Córdoba, 1999, 122-123.

${ }_{20}$ Sabrie, M.; Demore, M., Peintures romaines à Narbonne, décorations murales de l'antique province de Narbonnaise. 1991. 59-61.

21 Moraval, J.M.; Blanco, J. et Camps, C., «Depose et restauration d'une peinture islamique á Valence», Peinture Mural Romaine. Actes du X séminaire AFPMA, Vaison-la Romaine. Provence Alpes-Côte d'Azur-Conseil General du Vaucluse. 1987, 161-170.

22 Gárate Rojas, I., Las artes de la cal, Madrid 1994, 159. 
por ejemplo aumentar su trabazón, dureza y estabilidad ${ }^{23}$, además de retardar el proceso de secado por su higroscopicidad.

\subsection{Materiales y técnica de ejecución de las pinturas cordobesas de Madinat al-Zahrä' y Arrabales de Poniente}

En Arrabales de Poniente la técnica puede ser un temple de goma arábiga, en el que la acción de recarbonatación del mortero ha contribuido a reforzar la fijación de la capa pictórica; sin embargo, también podría tratarse de un temple de goma y cal que se prepararía mezclando el pigmento con agua de cal y goma arábiga. Como se ha podido comprobar en ocasiones, el aglutinante se ha perdido completamente $\mathrm{y}$, sin embargo, la película pictórica, aunque soluble en agua, presenta un aspecto consistente.

En estos zócalos la capa pictórica parece que no se pulimentó, ya que, además de observarse la huella del pincel, no se ha encontrado ningún fragmento con ese brillo característico típico de la pintura pulimentada.

En el fragmento procedente de Madīnat al-Zahrā'no se ha detectado aglutinante orgánico. El proceso utilizado podría ser el siguiente: en primer lugar se aplicaría la capa de mortero y, al hacerlo sobre una superficie grande, ésta quedaría prácticamente seca a nivel superficial cuando hiciera el dibujo preparatorio. Posteriormente se aplicaría el pigmento ${ }^{24}$ y finalmente se haría el pulido del mortero, con el cual, además de obtener una textura más fina para la capa pictórica, se conseguiría hacer aflorar a la superficie los restos de humedad e hidróxido cálcico que quedaran en el interior del mortero.

Como se puede comprobar, el proceso seguido coincide con el descrito por Mora, Mora y Phillippot para la pintura mural bizantina. Estos autores también dicen que la lechada de cal, cuando se mezcla con los colores y es aplicada sobre un enlucido casi seco, da a la pintura una tonalidad blanquecina, opaca, parecida al gouache; en cambio, cuando se da sobre un enlucido fresco, proporciona a la capa pictórica una transparencia grasa y una calidad untuosa, que permanece después del secado ${ }^{25}$, cualidades que se pueden observar en el fragmento de Madīnat al-Zahrä'.

En cuanto a la comparación de las pinturas califales, las de Medina Elvira no pueden relacionarse con las dos cordobesas por el sistema de trabajo, ya que, aunque se mantiene el uso del color almagra, en éstas el color no se aplica por la técnica del esgrafiado.

Sí hay que resaltar el aspecto pulido y brillante que presentan tanto las pinturas de Medina Elvira como el fragmento de Madīnat al-Zahrā', esto po-

${ }^{23}$ Gárate Rojas, I., Las artes de la cal, 122-126.

24 Debido a la procedencia arqueológica del fragmento y a la solubilidad de la goma arábiga en medio acuoso, no podemos descartar por completo el uso de aglutinante, ya que éste pudo perderse como consecuencia de los procesos de degradación sufridos.

${ }^{25}$ Mora, P.; Mora, L.; Philippot, P., Conservation of Wall Paintings, 107-115. 
dría deberse a que en los dos casos se realizaran expolitiones y también que en estos dos casos se ha comprobado el uso de aglutinantes orgánicos.

Respecto a los aditivos de los morteros, debemos señalar que de las muestras analizadas en Medina Elvira sólo una presentaba paja en el mortero, mientras que en las de Córdoba la presencia de ésta es constante.

\section{Conclusiones}

Comparando los morteros de la pintura mural califal con los hispano-romanos examinados, se puede observar un cambio apreciable, ya que, a pesar de que también son de cal, éstos presentan un árido compuesto fundamentalmente por arena de sílice sin adiciones de materia orgánica, mientras que los morteros califales son mucho más blancos y el árido empleado es una calcita muy pura o polvo de mármol. Sin embargo, la relación existente con los materiales de Qușayr 'Amra es más clara, ya que en ambos casos los últimos morteros son de un blanco purísimo y están compuestos por carbonato cálcico casi exclusivamente.

También destaca la existencia de paja en los morteros tanto en el fragmento de Madīnat al-Zahrä' como en Arrabales de Poniente, presencia que también se constataba en Medina Elvira y en Qușayr ${ }^{\mathrm{C}}$ Amra y que, sin embargo, no hemos identificado en la pintura mural de período hispanorromano.

En las capas de pintura examinadas del período romano no se han detectado aglutinantes orgánicos; por el contrario, en la pintura califal se utilizan de forma generalizada, al igual que ocurre en Qușayr ${ }^{\mathrm{C}} \mathrm{Amra}$.

La variedad de pigmentos es notablemente mayor en la pintura romana que en la califal, ya que mientras que en las primeras existe una gran diversidad de colores, en las segundas únicamente hemos encontrado uno o dos a lo sumo, si consideramos la documentación de Gómez Moreno y Torres Balbás, en la que se menciona la existencia de fragmentos de color ocre. Si bien evidentemente la riqueza cromática de los pigmentos en ${ }^{\mathrm{C}} \mathrm{Amra}$ tampoco tiene nada que ver con la austeridad del color de la pintura califal.

Como conclusión, podemos decir que, a pesar de las diferencias observadas entre las pinturas califales examinadas, en ellas se observan unos rasgos comunes que las vinculan más a la pintura mural oriental que a las hispanorromanas estudiadas *.

* Este trabajo no hubiera sido posible sin la colaboración de numerosas personas e instituciones, por ello queremos hacer constar nuestro agradecimiento a todos los que de una manera u otra han contribuido a su realización. Especialmente a D. Antonio Almagro Gorbea, de la Escuela de Estudios Árabes, CSIC, Granada; al Museo Arqueológico de Granada y a doña Concha San Martín, directora del mismo en el momento de la investigación; al Ayuntamiento de Córdoba y especialmente a D. Juan Francisco Murillo, Arqueólogo; al Museo Arqueológico de Córdoba y a su director, D. Francisco Godoy Delgado. 


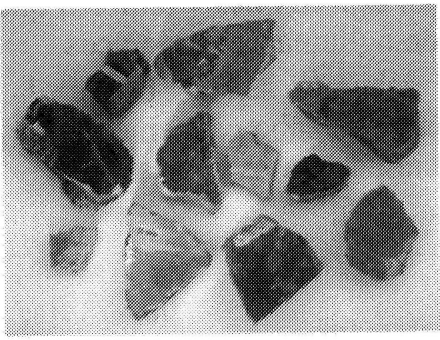

Fragmentos de los que se tomaron las muestras de Guadix

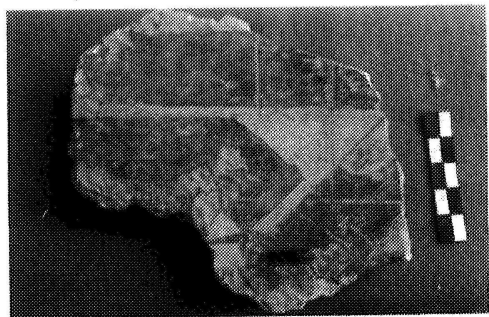

Madinat al-Zahrā', fragmento del Museo Arqueológico de Córdoba, N. ${ }^{\circ}$ de Registro 2801

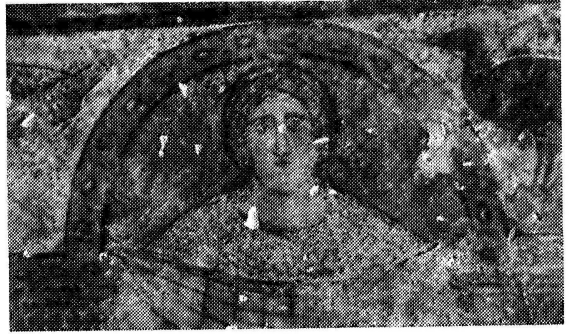

Qușayr ${ }^{\mathrm{C} A m r a}$, Jordania. Fragmento del salón del trono

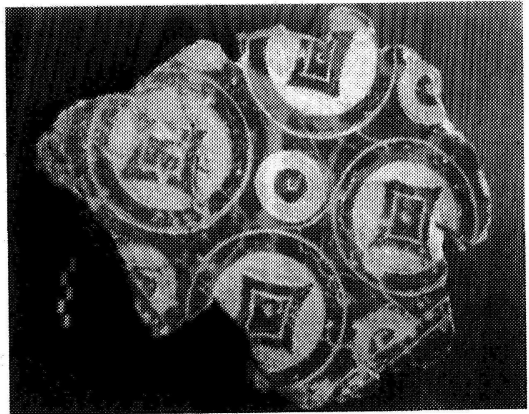

Medina Elvira, fragmento del Museo Arqueológico de Granada. $\mathrm{N}$. $^{\circ}$ de registro 920

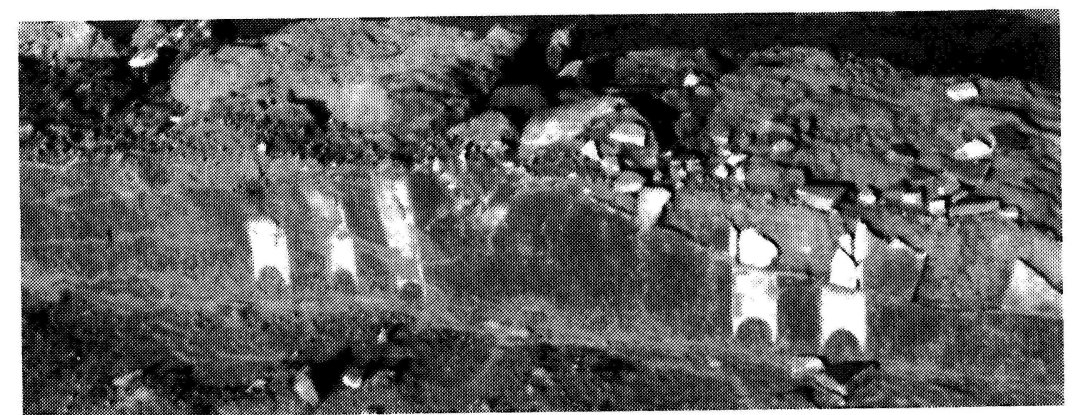

Zócalo procedente de la excavación de Arrabales de Poniente, Córdoba 